\title{
Evaluating the Performance of Selected Deicers Through On-Site Real-Time Road Test
}

\author{
Xiang Li ${ }^{1,2}$, Benoit Van Aken²*, Erica Mckenzie², Huichun Zhang ${ }^{2}$, Bechara Abboud ${ }^{2}$ and Wil- \\ liam Davenport ${ }^{3}$
}

${ }^{1}$ Advanced Research Institute of Multidisciplinary Science, Beijing Institute of Technology, China

${ }^{2}$ Department of Civil and Environmental Engineering, Temple University, Philadelphia, Pennsylvania, US

${ }^{3}$ Department of Transportation, US

*Corresponding author: Benoit Van Aken, Department of Civil and Environmental Engineering, Temple University, Philadelphia, Pennsylvania, US

To Cite This Article: Xiang Li, Benoit Van Aken, Erica Mckenzie, Huichun Zhang, Bechara Abboud, William Davenport. Evaluating the Performance of Selected Deicers Through On-Site Real-Time Road Test. Am J Biomed Sci \& Res. 2021 - 12(6). AJBSR.MS.ID.001806.

DOI: 10.34297/AJBSR.2021.12.001806.

Received: 眥 May 06, 2021; Published: 監 May 14, 2021

\begin{abstract}
Winter roadway maintenance operation is crucial for traffic safety. Deicers are commonly used to remove ice formed on roadways. In this paper, we proposed a new method to evaluate and compare the performance of different deicers. With the help of Road Weather Information System from PennDoT, the roadway friction changes after applying deicers were recorded along with the other variables including ground temperature, air temperature, snow layer thickness, relative humidity, barometric pressure, precipitation in 1 hour, wind Speed, deicer application rate and deicer type. A large amount of data could be easily collected. A linear regression model was fitted to predict the performance of each deicer and to compare the performances of different deicers. Another field test on parking lot was also conducted as a comparison. Two rankings from the two methods matched well with each other. Our work could provide a convenient and effective method for deicer evaluation especially suitable for governments but could be extended to a universal method.
\end{abstract}

Keywords: Deicers; Road test; Grip level; Regression; Traffic safety; Parking; Numerous; Transportation; Rock salt; Relative humidity

\section{Introduction}

Deicer products are commonly used in winter season to maintain the roadway clear and keep traffic safety [1-3]. Numerous efforts have been put by the researchers to evaluate the performance of deicer products through either laboratory test or field test [4-10]. But there are still issues remaining for the current test methods. Generally, laboratory testing could easily and economically quantify deicer performance and the results could be easy reproduced and extended $[11,12]$. However, the laboratory testing is very limited in a way that it is extremely difficult to mimic the actual field conditions such as varying temperatures, precipitation, wind, traffic, etc. in a lab, which in turn affect the effectiveness of laboratory testing [13]. In comparison field testing could replicate the actual conditions of deicer functioning leading to a much more accurate assessment $[14,15]$. Yet it can be complicated and costly to set up the experiments because of the large number of variables in the field environment that could play a role in the deicer performance and some of them are difficult to control or even to document [16]. On the other hand, state governments of U.S., mainly Department of Transportation, frequently did the winter roadway maintenance operations every winter and at the same time generated a large amount of data which could be potentially used.

To some extent, these operations are the most practical experiments we could do since the applied deicers are functioning at their real working conditions. If we could incorporate the deicer performance test into the normal routine roadway maintenance operation, a much more convenient and effective testing could be achieved. In this study we reported a new method of field testing of deicer performance which could be on-site and real time. Three 
deicer products were evaluated. Instead of setting up measurement devices by ourselves, our new method utilized the data collected from the routine operations of applying deicers for winter roadway maintenance of Pennsylvania Department of Transportation. But the deicer they applied was changed to the tested deicers. After collecting the data, we needed, we analyzed the data through building a statistical multiple regression model and successfully gave a ranking of performance of tested deicers. Our proposed method could give an effective evaluation of deicer performance with little cost and could be extended to be a universal method.

\section{Experiment Methods}

\section{Sample Preparation}

Rock salt and two of its potential substitutes Product A and Product B are studied in this work. Here rock salt is used as a reference. Product $\mathrm{A}$ is a magnesium chloride based liquid deicer containing $26 \%$ to $29 \%$ magnesium chloride. Before testing, Product A was added to $23.3 \%$ sodium chloride salt brine at $50 \%$ of the total volume of the solution (salt brine amended with Product A will be referred to as Product A hereafter). Product B is natural saltwater solution produced from ancient seas according to manufacturers. Product B contains a total of $22.1 \%$ chloride salts, including $7.7 \%$ sodium, $1.5 \%$ potassium, $10.3 \%$ calcium, and $2.6 \%$ magnesium chlorides, and is used as received.

\section{On-Road Test}

The application of deicers on the roadways were conducted by Pennsylvania Department of Transportation (PennDoT). The testing sites which were a series of $100 \mathrm{~m}$ long segment of roadway under normal operation were chosen based on historical data to ensure enough snowfall during winter. PennDoT have mounted grip level sensor on each testing site in prior to tests to track the level of grip of roadways. During the period of our experiments, a total of 17 snow events at testing sites were traced and studied, among which 10 events used Rock Salt as deicers, 2 events used Product A and 5 events used Product B.

During a snow event, the deicers were sprayed on the roadways at testing sites by the deicer spreading trucks from PennDoT. If the snow is heavy, the deicers could be sprayed multiple times in a snow event. After a snow event, data needed for evaluation of deicers were collected from Road Weather Information System (RWIS) and Automated Vehicle Location System (AVLS) provided by PennDoT. The RWIS continuously tracks and stores the following required data for each site: ground temperature $\left({ }^{\circ} \mathrm{F}\right)$, level of grip (an indicator of roadways friction used in RWIS), ice layer (in.), snow layer (in.), relative humidity (\%), precipitation in 1 hour, wind speed (mph), barometric pressure $(\mathrm{hPa})$ and camera shots of the road condition. The AVL gives the information about deicer usage including the type of deicer to use, amount of deicer to spread, time of spreading, and frequency of spreading. All the data were collected every five minutes.

\section{Statistical Analysis}

All the statistical analysis was conducted using a professional statistical analysis software $\mathrm{R} 囚$ (version 3.3.3). R provides a wide variety of statistical (e.g., linear, and nonlinear modeling, classical statistical tests, time-series analysis, classification, clustering) and graphical techniques, and it is highly extensible. We used the linear multiple regression models to model the performance of various deicers. We use the linear regression models to study the relationship between a scalar dependent variable Y (in our case the grip level) and one or more explanatory or independent variables X (e.g., variables recorded by the RWIS system, such as ground temperature, relative humidity, and snow layer thickness). We fitted the linear model using the Ordinary Least Square (OLS) approach. An outlier is an observation which is distant from other observations, due to variability in the measurement or experimental error. An outlier can cause problems in statistical analysis. In the analysis, we identify those observations with the corresponding standardized residues being larger than 3 or less than -3 as outliers and remove them to improve the model fit.

\section{Skid Resistance Test at Parking Lot}

Skid resistance was used to evaluate the effect of three deicer products on the surface conditions at the application rate of $500 \mathrm{lb}$ per lane mile. The skid resistance is measured using a British pendulum which is commonly used to assess the macrotexture of pavement surfaces $[17,18]$. The pendulum measures the frictional resistance between a rubber slider mounted on the end of a pendulum arm and the test surface. This provides a routine method of checking the resistance of wet and dry surfaces to slipping and skidding, both in the lab and on site. It is based on the Izod principle: a pendulum rotates about a spindle attached to a vertical pillar. At the end of the tubular arm a head of known mass is fitted with a rubber slider. The pendulum is released from a horizontal position so that it strikes the sample surface with a constant velocity. The distance travelled by the head after striking the sample is determined by the friction of the sample surface. A reading of Skid Resistance is obtained. This device is employed in this project to measure frictional properties of the pavement surface according to ASTM E303 Standard Test Method for Measuring Surface Frictional Properties Using the British Pendulum Tester [19]. Field testing was conducted at a controlled parking lot during snow events. A grid was set-up consists of 3'x3'squares (Figure S1). The products used were applied on test areas of $3 \mathrm{ft} \times 3 \mathrm{ft}$ for each product. The data was collected every 15 minutes. The measurement was repeated three times and average value was reported. 


\section{Results and Discussion}

Roadway Friction is crucial for traffic safety in winter season. Good friction between vehicle tires and roadway is required to keep the vehicle on the road during braking, accelerating, and turning [20]. The presence of snow and ice can greatly reduce friction such that almost any braking or sudden turn results in vehicles losing control and sliding. Roadway maintenance operations such as antiicing, plowing, deicing, and sanding are extremely necessary to restore the roadway friction to a safe level. Since roadway friction is so important that we could use it as an indicator to evaluate the performance of different deicer products. Another reason of using roadway friction as indicator is that the roadway friction could be quantitatively measured using sensors which is convenient for data collection and statistical analysis. Pennsylvania Department of Transportation (PennDoT) has developed a Road Weather Information System (RWIS) in which the roadway friction was continually measured and recorded as "grip level" (hereafter the friction is referred as grip level) for certain sections of roadways.

We chose fives testing sites with the largest possibility of snowing from those roadways mounted with friction sensors based on historical data. Once there is a snowfall occurring on the testing sites, PennDoT will send deicer spreading truck to apply certain type of deicers. With the help of RWIS, the grip level change after application of deicers could be recorded and analyzed. We called the continuous or intermittent snowfalls start and end within 24 hours a snow event. One snow event could include several snowfalls and multiple times of deicer spreading. A total of 17 snow events at all the testing sites were studied during the experiments. Among all the snow event studied, Rock Salt was used for 10 events, Product A was used for 2 events and Product B was used for 5 events. To demonstrate the data collection process, we use one snow event as an example. A snow event was recorded at a testing site approximately from 19:00 Dec 24th, 2017 to 12:00 Dec 25th, 2017 including four major snowfalls and five times deicing operations. According to the information from Automated Vehicle Location System (AVLS), the deicer-spreading trucks set off five times at 19:50 Dec 24th, 22:17 Dec 24th, 22:25 Dec 24th, 6:05 Dec $25^{\text {th }}$ and 6:15 Dec 25th.

For all the five times of spreading, the deicer used was Product A but the deicer application rate which is defined as the amount of deicer sprayed per mile (lb/mile) was different each time. The deicer application rate and deicer type used for each snow event was recorded for following statistical analysis. To study this snow event, we collected all the environmental information potentially related to the deicer performance from RWIS system, including ground temperature, air temperature, wind speed, relative humidity, and barometric pressure. The data was collected for 24 hours covering period of the studied snow event. The plots of collected data were shown in Figure1. From Figure1 we can see the average ground temperature at the location of testing site was around $30 \stackrel{\circ}{\circ}$. At nighttime, the temperature could fall below $32 \stackrel{\circ}{\circ}(0 \stackrel{\circ}{\circ})$ to $22 \stackrel{\circ}{\circ}$. The air temperature was slightly lower than ground temperature but had a similar trend. The wind was much stronger at night as indicated by the much larger wind speed at nighttime. From Figure $1 \mathrm{~b}$ we can see the relative humidity significantly increased from $80 \%$ to $100 \%$ during the period of $19: 00$ to $24: 00$ which is the signal of snowfall. The barometric pressure dropped at night which is normal due to the decreased air temperature at night.

The data directly related to the deicer performance such as grip level, thickness of snow layer and precipitation 1-hour was also obtained from the RWIS system. In Figure 2 we plotted the grip level data together with thickness of snow layer and precipitation in 1 hour to demonstrate the effect of deicers on the change of grip level. We observed that the grip level decreased before or shortly after the onset of the snow precipitation, which was in turn followed by an increase of the snow layer. After the 1st deicer spreading truck passage at 19:50 Dec $24^{\text {th }}$ indicated as the first vertical dashed line in the figure 1a small increase of grip level was observed which we believed was the effect of deicers. At around 21:30 the snow precipitation and snow layer thickness reached a top value and the grip level dropped dramatically to almost wet friction. The following two times of deicer spreading at 22:17 and 22:25 Dec 24th resulted in a sharp increase of the grip level. Since then, the grip level maintained at a normal state until the next snow precipitation at around 2:30 Dec 25th when the grip level rapidly decreased to a low value (Figure1a, b).

The following truck passage at 6:05 Dec 25th and 6:15 Dec 25th did not have a significant effect on the grip level because of ongoing large snow precipitation and thick snow layer accumulated. From 9:36 the grip level started to increase probably due to the applied deicer and increased ground/air temperature. The same data collection process was repeated for all the 18 snow events studied in this work. Putting all collected data together, we got a data set (10x2005 matrix) including total ten variables: grip level, ground temperature, air temperature, snow layer thickness, relative humidity, barometric pressure, precipitation in 1 hour, wind Speed, deicer application rate and deicer type (categorical variables). It should be noted here, a potentially important factor, traffic density, was not considered in this study due to the lack of information. The pavement type and texture are identical for all the testing sites therefore are not considered as a variable in this study. But for other cases it may need to be considered. Solar radiation, another parameter may potentially influence the deicer performance was also not included in current study (Figure2). 
(a)

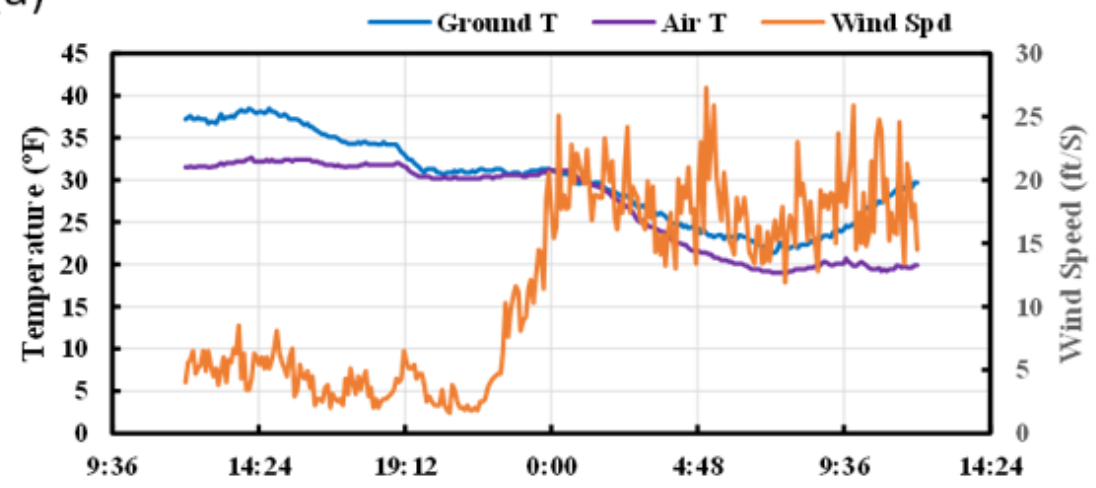

(b)

Time

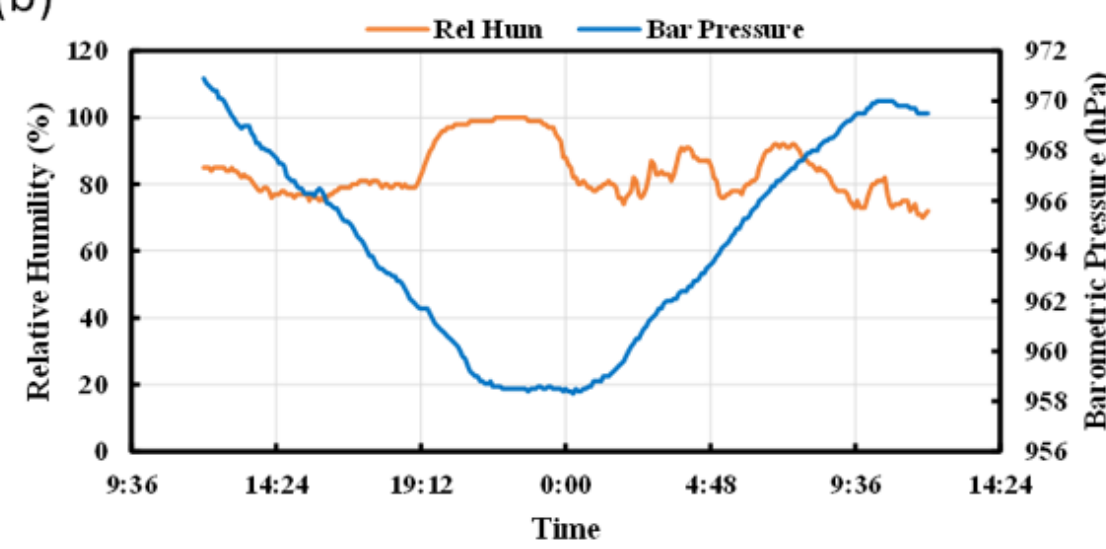

Figure 1: The collected weather data from RWIS during a snow event at testing site. (a) Plot of ground Temperature, air temperature and wind speed versus Time. (b) Plot of relative humidity and barometric pressure versus Time.

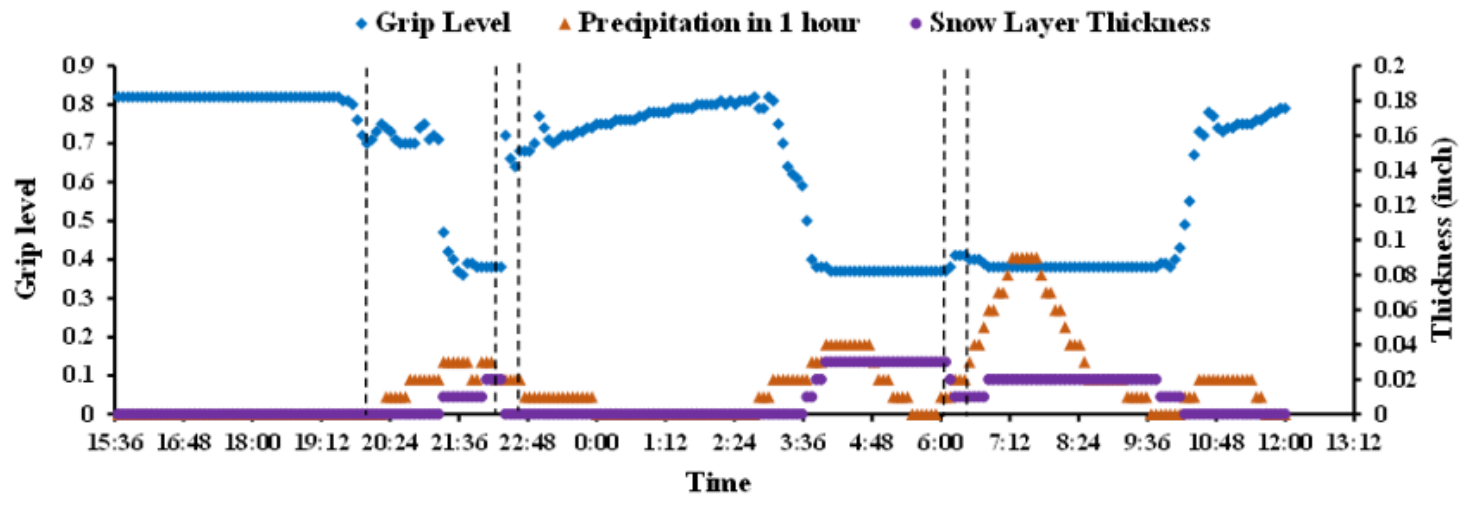

Figure 2: The measured grip level, snow layer thickness and precipitation in 1-hour at testing site during a snow event. Vertical dashed lines indicate the deicer spreading truck passages.

To evaluate the performance of each deicer, we built a linear multiple regression model using the collected data. The regression analysis was run using the grip level as the response variable and a set of explanatory variables, including ground temperature, air temperature, snow layer thickness, relative humidity, barometric pressure, precipitation in 1 hour, wind speed, deicer application rate, and deicer type (categorical variables). The model suggested by the stepwise regression is: Grip level $\sim$ Ground Temperature+ Air Temperature+ Snow Layer Thickness+ Relative Humidity+ Precipitation in 1 Hour+ Wind Speed+ Deicer Application Rate+ Deicer Type (Intercept). Table 1 shows the coefficient for the model fitting and Table 2 shows the modeled equation for all the three deicers. The Residual standard error is 0.1085 on 1960 degrees of freedom (8 observations deleted due to meaninglessness). After 
removing 24 outliers, the R-square of the model is 0.7166 . The adjusted R-squared is 0.7149; F-statistic is 413 with degrees of freedom as 12 and 1960 . The resultant $\mathrm{p}$-value is $\mathrm{p}$-value $<2.2 \mathrm{e}-16$. From the table we could found some coefficient in the fitted model seems unphysical. For example, a positive coefficient for the term of precipitation in 1 hour means the grip level becomes larger with the increased precipitation.

Table 1: List of explanatory variables coefficient and their statistical significance.

\begin{tabular}{|c|c|c|c|c|c|}
\hline & Estimate & Std. Error & t value & $\operatorname{Pr}(>|t|)$ & Sig \\
\hline \multirow{3}{*}{$\begin{array}{l}\text { Deicer Type } \\
\text { (Intercept) }\end{array}$} & 6.5300 if Product A & $6.57 \mathrm{E}-01$ & 9.94 & $<2 \mathrm{e}-16$ & $* * *$ \\
\hline & 6.5846 if Product B & $1.23 \mathrm{E}-02$ & 4.422 & $1.03 \mathrm{E}-05$ & $* * *$ \\
\hline & 6.5278 if Rock Salt & 8.95E-03 & -2.862 & 0.00435 & $* *$ \\
\hline Ground T & $3.64 \mathrm{E}-03$ & $1.09 \mathrm{E}-03$ & 3.338 & 0.000861 & $* * *$ \\
\hline Air T & $-5.89 E-02$ & 7.53E-03 & -7.828 & $8.02 \mathrm{E}-15$ & $* * *$ \\
\hline Snow Layer & $-8.04 E+00$ & $2.71 \mathrm{E}-01$ & -29.717 & $<2 \mathrm{e}-16$ & $* * *$ \\
\hline Rel Hum & $-2.66 \mathrm{E}-02$ & $2.45 \mathrm{E}-03$ & -10.877 & $<2 \mathrm{e}-16$ & $* * *$ \\
\hline Barom Press & $-3.52 \mathrm{E}-03$ & $6.07 \mathrm{E}-04$ & -5.797 & $7.85 \mathrm{E}-09$ & $* * *$ \\
\hline Prec $1 \mathrm{~h}$ & $7.36 \mathrm{E}-01$ & $2.27 \mathrm{E}-01$ & 3.251 & 0.00117 & $* *$ \\
\hline Wind Spd & $-8.48 E-03$ & 8.85E-04 & -9.583 & $<2 \mathrm{e}-16$ & $* * *$ \\
\hline App Rate & $-3.54 \mathrm{E}-04$ & $2.52 \mathrm{E}-05$ & -14.028 & $<2 \mathrm{e}-16$ & $* * *$ \\
\hline
\end{tabular}

Table 2: The model fitting equations.

\begin{tabular}{|c|c|}
\hline Deicer & Model Equation \\
\hline Product A & $\begin{array}{c}\text { Grip Level =6.5300+3.64E-03×GroundT-5.89E-02×AirT }-8.04 \times \text { SnowLayer }-2.66 \mathrm{E}-02 \times \text { RelHum }-3.52 \mathrm{E}-03 \times \text { BaromPress }+7.36 \mathrm{E}- \\
01 \times \text { Pre } 1 \mathrm{~h}-8.48 \mathrm{E}-03 \times \text { windSpeed }-3.54 \mathrm{E}-04 \times \text { AppRate }\end{array}$ \\
\hline Product B & 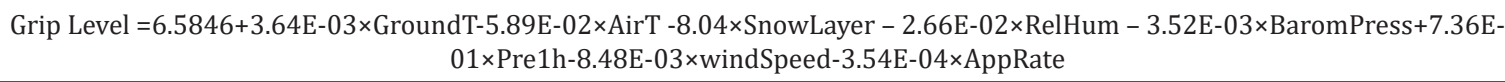 \\
\hline Rock Salt & 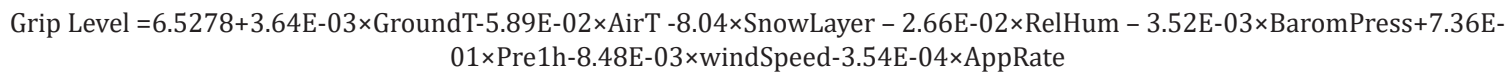 \\
\hline
\end{tabular}

Also, a negative coefficient for the deicer application rate means more deicer applied will lead to a lower grip level. Such unphysical consequence comes from the fact that the explanatory variables correlate each other, e.g., multicollinearity. As seen from the correlation matrix shown in Table S1, good correlations (coef $\geq 6.0$ ) exist for some explanatory variables (shaded in grey). Therefore, current fitted model only has a meaning in mathematics but cannot be interpreted in physical approach. Since multicollinearity does not affect the overall fitting and our fitted model has a satisfactory R-squared, a model containing only independent explanatory variables was not pursued in this work. The different deicer type has different intercept. The difference between two intercepts represents the average difference between the grip levels when applying different type of deicers. Thus, the ranking of the intercepts corresponding to different deicer type is also the ranking of average performance of different deicers. From Table 1 we can see in average, Product B has the significant better performance than Product A and Rock Salt, and Product A is slightly better than Rock Salt (Table1,2).

To verify this method, we further conducted another skid test at a parking lot using the same deicers. The tested parking lot area initially covered by snow was divided into $3 \mathrm{ft} \times 3 \mathrm{ft}$ squares (Figure S1). Each square was treated with different deicer product. The skid was measured with a British pendulum. Figure 3 shows the measured skid resistance at the test areas after the first and second application of deicer products. The horizontal lines show the skid value for the test area in dry conditions at the same temperature, and the skid value of the surface after plowing the snow and before the application of the product, respectively. In effect these two lines show the drop in skid due to the snow event after plowing. Therefore, they provide a good reference for the effectiveness of the products in attaining skid resistance close to the dry conditions. In addition, the time profile provides insight to the time needed for the product to achieve a safe level of skid resistance and how long it can maintain this level between applications. As can be noted in Figure 3 , in general all the products show increase in the skid resistance with some incidence of temporary drop during the testing period. All three deicers increased the skid resistance for the reading at 15 minutes from the first application. The resistance continued to increase for the 30-minute reading. However, the resistance decreased as the snow precipitation took place. 


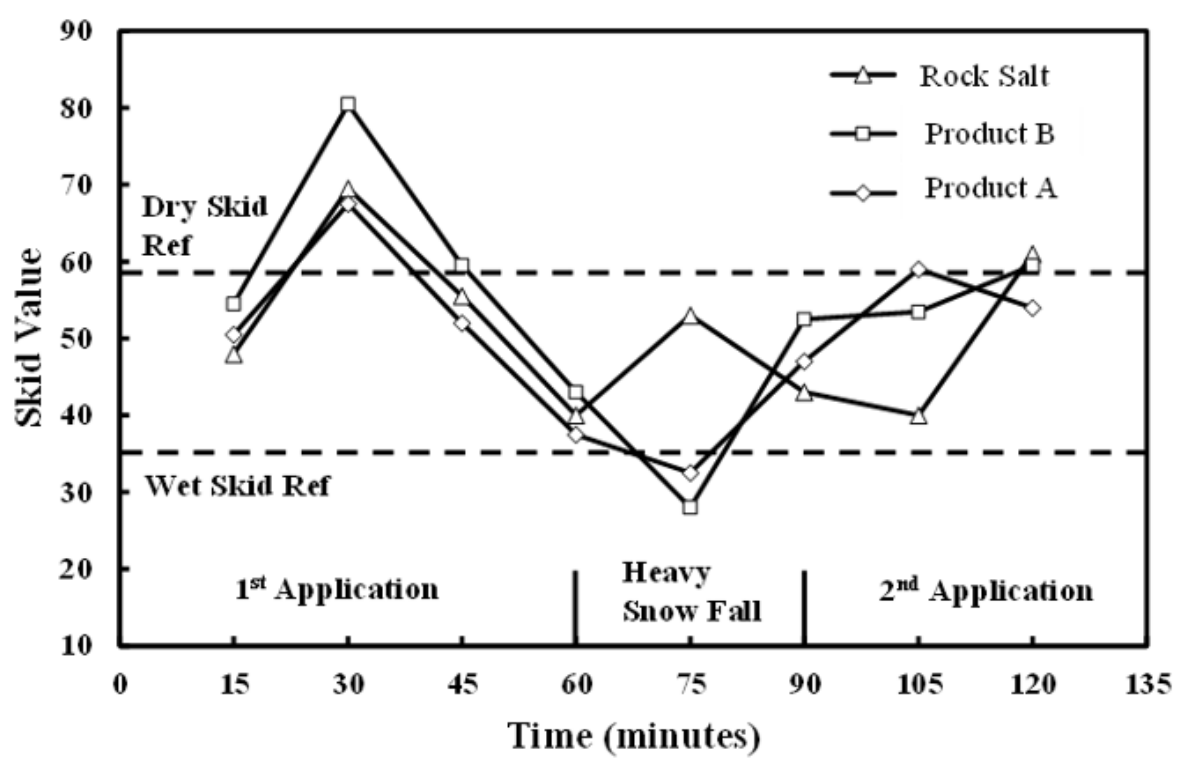

Figure 3: Comparison of Skid Results for all Products. The horizontal dashed lines show the skid value for the test area in dry condition (Dry Skid Reference) and the skid value of the surface after plowing the snow and before the application of deicers.

After the 60-minute mark, heavy snow started falling for about 10 minutes followed by light precipitation for the rest of the testing period. The second application increased the skid resistance to the same level attainted under dry conditions at 105 minutes. The final reading shows that the product can maintain similar levels of the skid value. It is important to note that the reading at 75 minutes (15 minutes after the second application) did not show any improvement in skid resistance compared to the wet reference condition. This could be due to the heavy snow fall that started at the 60 minutes after the beginning of testing. The Rock Salt performance was consistently below that of the dry condition except for the final reading where the reading was at the level of the dry condition. Testing results show general improvement in skid resistance compared to wet conditions (plowing only with no deicers) except for a few data points during the test. During first application, Product B leaded to a larger skid value than did of Product A and Rock Salt which two had a similar skid value. During second application, Product A and Product B performed similar and were much better than Rock Salt as evidenced by much larger skid value than Rock Salt. Overall, Product B had the best performance and Rock Salt had the least effect on skid resistance among all three deicers. This ranking matches the result of previous on-road test which validates our method (Figure 3).

\section{Conclusion}

In this paper, we reported a method of on-road evaluating the performance of three deicers in the practical working condition. The deicer performance was assessed based on the roadway friction measured by grip level sensors. The related data including ground temperature, air temperature, snow layer thickness, relative humidity, barometric pressure, precipitation in 1 hour, wind Speed, deicer application rate and deicer type were collected from RWIS and AVLS of PennDoT. A linear multiple regression model was built to fit the collected data. From the fitted equation, the deicing performance of each deicer could be predicted and the average difference between the deicing performances of three deicers could be evaluated. We compare our result with a field test using "traditional" method at a parking lot. The results matched well which validates our method. Our work proposed a new approach for deicer evaluation and could help the selection of deicer products.

\section{Acknowledgement}

The authors acknowledge the financial support from Pennsylvania Department of Transportation.

\section{References}

1. Fischel M (2001) Evaluation of selected deicers based on a review of the literature.

2. Ramakrishna DM, T Viraraghavan, (2005) Environmental impact of chemical deicers-a review. Water Air and Soil Pollution 166(1-4): 49-63.

3. Shi X, Laura Fay, Zhengxian Yang, Tuan Anh N, Yajun Liu (2009) Corrosion of deicers to metals in transportation infrastructure: Introduction and recent developments. Corrosion reviews 27(1-2): 23-52.

4. Chappelow CC, McElroy, Albert Dean, Blackburn, Robert R, et al. (1992) Handbook of test methods for evaluating chemical deicers.

5. Akin M, X Shi (2012) Development of standard laboratory testing procedures to evaluate the performance of deicers. J Testing Evaluation 40(6): 1015-1026.

6. Alatyppö V, Jutila K, Efficiency of runway de-icing chemicals in practice.

7. Al-Qadi IL, Louliz, Flintsch, Roosevelt, Decker, et al., (2002) Feasibility of using friction indicators to improve winter maintenance operations and mobility. Transportation Research Board, National Research Council. 
8. Bernardin S, Laforte JL, Louchez P, (1996) Runway Deicer StudyDetermination of a Testing Procedure. Transport Canada Airports Final Report.

9. Cuelho E, et al., (2010) Establishing best practices for removing snow and ice from California roadways. Presentation to the Winter Maintenance Committee at the 89th.

10. Ganjyal G, Fang Q, Hanna MA, (2007) Freezing points and small-scale deicing tests for salts of levulinic acid made from grain sorghum. Bioresour Technol 98(15): 2814-2818.

11. Nixon WA. Ice melting performance for ice-control chemicals. Citeseer.

12. Luker C, B Rokosh, T Leggett. Laboratory melting performance comparison: rock salt with and without prewetting

13. Leggett TS, P Eng, (1999) Temperature and humidity effects on the coefficient of friction value after application of liquid anti-icing chemicals. Final Report, Forensic Dynamics Inc., Kamloops.

14. Shi X, et al., (2009) Evaluation of alternative anti-icing and deicing compounds using sodium chloride and magnesium chloride as baseline deicers-Phase I. Colorado Department of Transportation Dtd Applied Research and Innovation Branch.
15. Fay L, X Shi, (2012) Environmental impacts of chemicals for snow and ice control: state of the knowledge. Water Air Soil Pollution 223(5) 2751-2770.

16. Anburaj Muthumani, Laura Fay, Michelle Akin, Shaowei Wang, Jing Gong, et al. (2014) Correlating lab and field tests for evaluation of deicing and anti-icing chemicals: A review of potential approaches. Cold Regions Science and Technology 97: 21-32.

17. Lee Y, Fwa T, Choo Y, (2005) Effect of pavement surface texture on british pendulum test. J Eastern Asia Society for Transportation Studies 6: 1247-1257.

18. Qing Lu, Bruce Steven, (1971) Friction testing of pavement preservation treatments: literature review. Compare.

19. Astm, (2013) Standard test method for measuring surface frictional properties using the British pendulum tester.

20. Nixon WA, The Potential of Using Friction as a Tool for Winter Maintenance. Final Report of Project TR. 400. 